\title{
Differential effects of acute and chronic treatment with the flavonoid chrysin on anxiety-like behavior and Fos immunoreactivity in the lateral septal nucleus in rats
}

\author{
LEÓN JESÚS GERMÁN-PONCIANO ${ }^{1,2}$ \\ ABRAHAM PUGA-OLGUÍN ${ }^{1,2}$ \\ MARÍA DE JESÚS ROVIROSA-HERNÁNDEZ ${ }^{3}$ \\ MARIO CABA ${ }^{4}$ \\ ENRIQUE MEZA \\ JUAN FRANCISCO RODRÍGUEZ-LANDA ${ }^{2,5, *}$ \\ ${ }^{1}$ Programa de Posgrado en Neuroetología \\ Instituto de Neuroetología, Universidad \\ Veracruzana, Xalapa 91190, Veracruz, México \\ ${ }^{2}$ Laboratorio de Neurofarmacología \\ Instituto de Neuroetología, Universidad \\ Veracruzana, Xalapa 91190, Veracruz, México \\ ${ }^{3}$ Instituto de Neuroetología, Universidad \\ Veracruzana, Xalapa 91190, Veracruz, México \\ ${ }^{4}$ Centro de Investigaciones Biomédicas \\ Universidad Veracruzana, Xalapa 91190 \\ Veracruz, México \\ ${ }^{5}$ Facultad de Química Farmacéutica Biológica \\ Universidad Veracruzana, Xalapa 91000 \\ Veracruz, México
}

\begin{abstract}
The aim of this study was to compare the effects of acute (a single injection) and chronic (21 consecutive days) treatments with chrysin 2,4 , and $8 \mu \mathrm{mol} \mathrm{kg}^{-1}$ on anxiety-like behavior and Fos immunoreactivity in the lateral septum nucleus (LSN), a structure that is involved in the regulation of anxiety, in male Wistar rats. These effects were compared with the clinically effective anxiolytic diazepam $7 \mu \mathrm{mol} \mathrm{kg}{ }^{-1}$. The results showed that acute, but not chronic treatment, with $4 \mu \mathrm{mol} \mathrm{kg}{ }^{-1}$ chrysin exerted anxiolytic- and antidepressant-like effects with these effects being similar to that of diazepam. Also, none of the above-mentioned treatments did alter Fos immunoreactivity in the LSN, but a tendency towards the reduction of this variable was detected with chrysin $4 \mu \mathrm{mol} \mathrm{kg}{ }^{-1}$ and diazepam $7 \mu \mathrm{mol} \mathrm{kg}{ }^{-1}$. Altogether, results suggest that chrysin exerts anxiolytic-like effects, however, it can produce pharmacological tolerance after repeated use, similar to benzodiazepines.
\end{abstract}

Keywords: chrysin, anxiolytic, elevated plus maze, Fos protein, lateral septal nucleus

Accepted September 4, 2019

Published online September 19, 2019

Flavonoid chrysin (5,7-dihydroxyflavone) is a partial agonist of $\gamma$-aminobutyric acid-A $\left(\mathrm{GABA}_{\mathrm{A}}\right)$ receptors (1). Acute injection of a low dose $\left(4 \mu \mathrm{mol} \mathrm{kg}{ }^{-1}\right)$ of this flavone produces anxiolytic-like effects in mice, without producing significant changes in spontaneous locomotor activity (1). Higher doses of chrysin $\left(20\right.$ and $80 \mu \mathrm{mol} \mathrm{kg}^{-1}$ p.o., daily, for 28 days) exerted antidepressant-like effects in mice that were exposed to chronic unpredictable mild stress and forced swim test (2). The repeated use of anxiolytic drugs, such as benzodiazepines (e.g., diazepam), reduces its pharmacological actions in the long term (3). Also, no comparative studies have explored the acute and chronic actions of similar doses of chrysin on anxietyand depression-like behavior. We sought to compare the acute and chronic effects of chrysin

\footnotetext{
*Correspondence; e-mail addresses: juarodriguez@uv.mx
} 
on anxiety- and depression-like behavior and the activation of a brain structure that is involved in the modulation of anxiety and depression (i.e., the lateral septal nucleus [LSN]) to gain a better understanding of its potential therapeutic use in the long term.

The LSN is involved in many emotional and affective disorders, such as anxiety and depression. For example, the activation of LSN neurons may contribute to the inhibition of fear-associated behaviors, and neuronal inhibition of the LSN may be related to anxiolytic-like effects (4). An increase in Fos immunoreactivity in the LSN was observed in rats that were exposed to stressful situations (i.e., the forced swim test) and situations that produce anxiety, such as the light-dark box test (5). Treatment with anxiolytic drugs, such as diazepam, reduced Fos immunoreactivity in the LSN in rats that were exposed to stressful situations (6). These data support the participation of the LSN in anxiety and the mechanism of action of anxiolytic drugs.

The present study investigates the effects of acute and chronic treatment with three doses of chrysin in Wistar rats that were subjected to a behavioral test battery composed of the elevated plus maze (EPM), locomotor activity test (LAT), and forced swim test (FST). We have also performed the Fos protein labeling to explore the relationship between the behavioral effects of chrysin and activity of the LSN.

\section{EXPERIMENTAL}

\section{Animals}

Ninety adult male Wistar rats, 3 months old and weighing 250-300 g at the beginning of the experiments, were used. The rats were housed in Plexiglas cages (five rats per cage) under a $12 \mathrm{~h} / 12 \mathrm{~h}$ light/dark cycle (light on at 7:00 AM) at an average temperature of $25 \pm 1^{\circ} \mathrm{C}$ with ad libitum access to purified water and food (Nutri-cubos Purina, Agribrands Purina México, México).

The experimental procedures considered the international and national ethical guidelines, the National Institutes of Health Guide for the Care and Use of Laboratory Animals (7) and the official Mexican guidelines Especificaciones Técnicas para la Producción, Cuidado y Uso de Animales de Laboratorio (8). All efforts were made to minimize animal discomfort during the study.

\section{Experimental groups and treatments}

Acute effects of chrysin and diazepam. - Forty-five rats were assigned to five independent groups ( $n=9$ rats per group). The control group received the vehicle (a mixture of $14 \%$ propylene glycol, $1 \%$ Tween 80 and $85 \%$ injectable sterilized water) in which chrysin and diazepam were dissolved. The other three groups received 2, 4 and $8 \mu \mathrm{mol} \mathrm{kg}{ }^{-1}$ chrysin (SigmaAldrich, USA). The last group received $7 \mu \mathrm{mol} \mathrm{kg} \mathrm{g}^{-1}$ diazepam (Valium solution injectable, Productos Roche, México). These doses were selected because $4 \mu \mathrm{mol} \mathrm{kg}{ }^{-1}$ chrysin was shown to produce anxiolytic-like effects at the preclinical level in mice (1). To generate a dose-response curve, we included two additional doses of chrysin $(0.5 \times$ and $2 \times$ the effective dose that produces anxiolytic-like effects). The dose of diazepam was based on its anxiolytic-like effects in experimental models of anxiety, including the EPM (9). The injections were given intraperitoneally (i.p.) in a volume of $1 \mathrm{~mL} \mathrm{~kg}^{-1}$ in a single injection (acute treatment). 
Sixty minutes after the injection, the rats were evaluated in the behavioral test battery, including elevated plus maze (EPM), locomotor activity test (LAT) and forced swim test (FST). Ninety minutes after the last behavioral test, five rats from each group were euthanized and perfused to obtain brains to immunohistochemically analyze Fos protein levels in the LSN.

Chronic effects of chrysin and diazepam. - Another 45 rats were assigned to five experimental groups ( $n=9$ rats per group) that received the same drugs and doses used for the acute treatment, except that the rats received the treatments once daily for 21 consecutive days (chronic treatment). Sixty minutes after the last injection, the rats were evaluated in the EPM, LAT and FST. Ninety minutes after the last behavioral test (day 21 of treatment), five rats from each group were euthanized and perfused to obtain brains to immunohistochemically analyze Fos protein levels in the LSN.

\section{Behavioral tests}

The rats were evaluated in a behavioral test battery that began with the EPM ( $5 \mathrm{~min})$, followed by the LAT ( $5 \mathrm{~min}$ ) and FST ( $6 \mathrm{~min}$ ). Approximately 3 min elapsed between tests. Two blinded observers measured the behavioral variables in each behavioral test using ex profeso software until at least $95 \%$ agreement was reached between observers. We used a battery of behavioral tests to reduce the number of animals that were used in this study in agreement with the ethical recommendations of the $3 \mathrm{R}$ principles in preclinical research (10).

Elevated plus maze. - The apparatus consisted of two opposite open and closed arms that were set in a plus configuration. The apparatus was illuminated at 40 lux as described by Contreras et al. (9). A digital video camera (DCR-SR42, 40× optical zoom, Carl Zeiss lens, Sony, Japan) was installed above the apparatus to record behavioral activity. The following variables were evaluated: (i) time spent on the open arms, (ii) number of entries into the open arms, (iii) total number of arm entries (open arms + closed arms), and (iv) percentage of open arm entries ([(open arm entries)/(total arm entries)] × 100). Additionally, as an integrative measure, the anxiety index (AI) was calculated according to the following equation. After the EPM, the rats were evaluated in the LAT.

$\mathrm{AI}=1-\{[($ open arm time/test duration $)+($ open arm entries/total number of entries $)] / 2\}$

Locomotor activity test. - To evaluate pharmacological effects on spontaneous locomotor activity, grooming, and rearing, the rats were individually subjected to a 5-min LAT. An opaque Plexiglas cage $(44 \mathrm{~cm} \times 33 \mathrm{~cm})$ with $20 \mathrm{~cm}$ high walls was used to identify or discard locomotor changes (i.e., hypoactivity, hyperactivity, or no change) that are associated with treatments and could interfere with behavior in the EPM (9). The cage floor was delineated into 12 squares $(11 \mathrm{~cm} \times 11 \mathrm{~cm})$. A digital video camera (DCR-SR42) was installed above the cage to record spontaneous behavioral activity. The following variables were evaluated: (i) number of squares crossed (crossings), (ii) time spent rearing (in seconds), and (iii) time spent grooming (in seconds), including paw licking, nose/face grooming, head washing, body grooming/scratching, leg licking, and tail/genital grooming. After each test session, the EPM and locomotor activity apparatus were carefully cleaned with $15 \%$ ethanol to remove the scent of the previously evaluated rat. After the LAT, the rats were evaluated in the FST. 
Forced swim test. - For this experimental protocol, the method described by Borsini was used (11), with modifications of the shape and size $(26 \mathrm{~cm} \times 29 \mathrm{~cm}$ base, $50 \mathrm{~cm}$ height) of the tank. After the LAT session, each rat was placed in a glass tank that was filled with water to a depth of $30 \mathrm{~cm}$ at a temperature of $25 \pm 1{ }^{\circ} \mathrm{C}$. The rat was subjected to a single 6-min forced swim session, and the total time of immobility was recorded only during the last $4 \mathrm{~min}$ (11). The total immobility time was the sum of all immobility periods that were $>2 \mathrm{~s}$ during the last $4 \mathrm{~min}$ of the session. Immobility was assumed when the rat made only the minimum movements that were necessary to keep its head above the water surface, without leading to water displacements that moved the rat's body around the tank, which is considered a measure of depression-like behavior. After the FST, five rats from each group were anesthetized to extract their brains and process them for immunohistochemical study and quantify Fos immunoreactivity in the LSN.

\section{Fos immunoreactivity in the LSN}

Ninety minutes after the FST, the rats were anesthetized with an overdose of sodium pentobarbital (Sedalpharma, Pet's Pharma, México; $0.4 \mathrm{mmol} \mathrm{kg}^{-1}$, i.p.) and transcardially perfused with $0.9 \%$ saline, followed by $4 \%$ paraformaldehyde in phosphate buffer $(\mathrm{PB}, 0.1$ mol L-1, pH 7.4). Brains were immediately removed, cryoprotected in serial dilutions of sucrose (10, 20 and $30 \%$ ) in PB, and coronally sectioned at $50 \mu \mathrm{m}$ with a cryostat (Microm HM 505N, Microm International GmbH, Germany) at $-22^{\circ} \mathrm{C}$. Serial sections were collected

a)

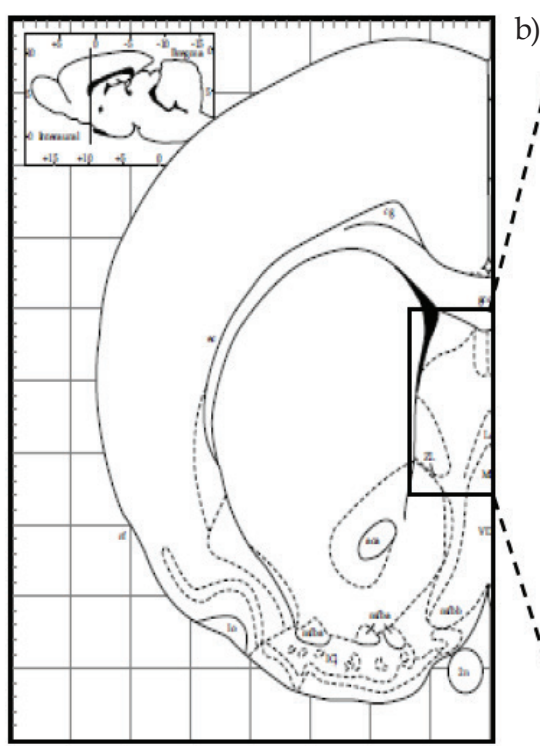

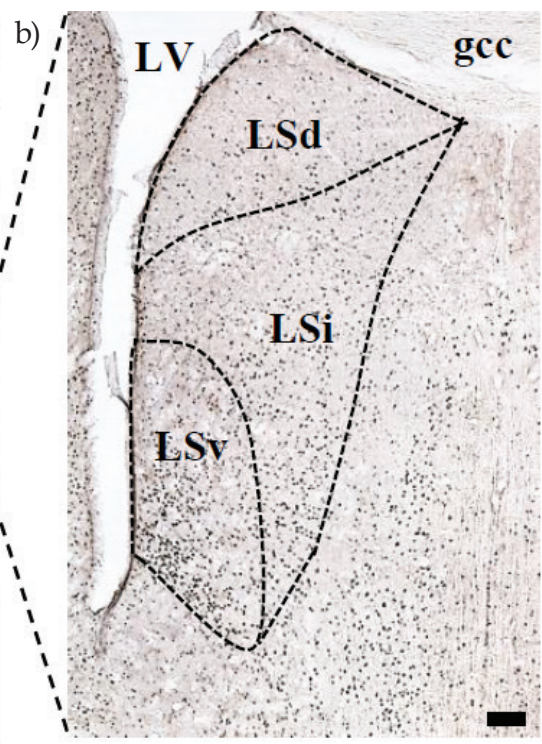

Fig. 1. Lateral septal nucleus: a) black rectangle indicates the LSN, adapted from Paxinos and Watson (13), b) Photomicrograph representing the division of the LSN where Fos immunoreactivity was measured as indicated in methods (LV - lateral ventricle, gcc - genu of the corpus callosum, LSd - dorsal lateral septum, LSi - intermediate lateral septum, LSv - ventral lateral septum). Black dots: Fos immunoreactivity, scale bar $=100 \mu \mathrm{m}$. 
in incubation boxes with PB. Fos immunohistochemistry was performed using a free-floating technique. One of every four sets of sections was used for Fos immunoreactivity as described previously (12).

To quantify Fos immunoreactivity in the LSN, the sections were examined under bright-field illumination with an Olympus BX41 microscope (Alta Tecnología en Laboratorios, México) at 10× and 20× magnifications. The LSN was analyzed bilaterally, including the dorsal $\left(75,000 \mu \mathrm{m}^{2}\right)$, intermediate $\left(200,000 \mu \mathrm{m}^{2}\right)$, and ventral $\left(150,000 \mu \mathrm{m}^{2}\right)$ areas. For quantification and statistical analysis, the number of Fos-immunoreactive cells in the LSN was counted in the following stereotaxic coordinates: interaural $9.70 \mathrm{~mm}$, bregma $0.70 \mathrm{~mm}$ (13) using a $10 \times 10$ grid $(500 \times 500 \mu \mathrm{m})$. The average number of Fos-expressing cells was calculated for each experimental group (Fig. 1).

\section{Statistical analysis}

The data were analyzed using one-way analysis of variance (ANOVA), with treatment as the independent factor. Non-parametric data were analyzed using the Kruskal-Wallis test. Values of $p \leq 0.05$ in the ANOVA were followed by the Student-Newman-Keuls post hoc test. The results are expressed as mean \pm standard error.

\section{RESULTS AND DISCUSSION}

\section{Acute effects of chrysin and diazepam}

Elevated plus maze. - The analysis of the time spent and the percentage of entries into the open arm showed significant differences $\left(F_{4,40}=3.859, p=0.010 ; F_{4,40}=3.197, p=0.023\right.$, resp.) between treatments. Chrysin $\left(4 \mu \mathrm{mol} \mathrm{kg}{ }^{-1}\right)$ significantly increased both variables, compared with the vehicle group, and this effect was similar to diazepam $\left(7 \mu \mathrm{mol} \mathrm{kg} \mathrm{kg}^{-1}\right)$ (Figs. 2a,b). An increase in these two variables is considered as a principal indicator of an anxiolytic-like effect (14). Clinically effective anxiolytic drugs (e.g., diazepam), and some secondary metabolites of plants with anxiolytic potential (e.g., flavonoids and phytoestrogens) increase the time spent and the percentage of entries into the open arms $(1,9)$ supporting an anxiolytic-like effect.

The analysis of the anxiety index confirmed the anxiolytic-like effect of chrysin in the EPM. The anxiety index was significantly affected by the treatment $\left(F_{4,40}=3.988, p=0.008\right)$ : chrysin $\left(4 \mu \mathrm{mol} \mathrm{kg}{ }^{-1}\right)$ and diazepam $\left.(7 \mu \mathrm{mol} \mathrm{kg})^{-1}\right)$ significantly decreased this variable compared with the vehicle group (Fig. 2c). This effect has been reported in rats treated with clinically effective anxiolytic drugs (15), supporting the anxiolytic-like effect of acute treatment with chrysin.

In regard to the total number of arm entries and number of entries into the open arms, no significant difference was observed between the vehicle and either of the test groups. Therefore, in the present study, we were able to discard non-specific motor effects of the treatments and confirm the anxiolytic-like effect of chrysin and diazepam.

Locomotor activity test. - The LAT was performed in order to discard or identify motor changes that were associated with the treatments and could interfere with the interpretation of the behavior displayed by the rats in the EPM. In this study, no significant differ- 
a)

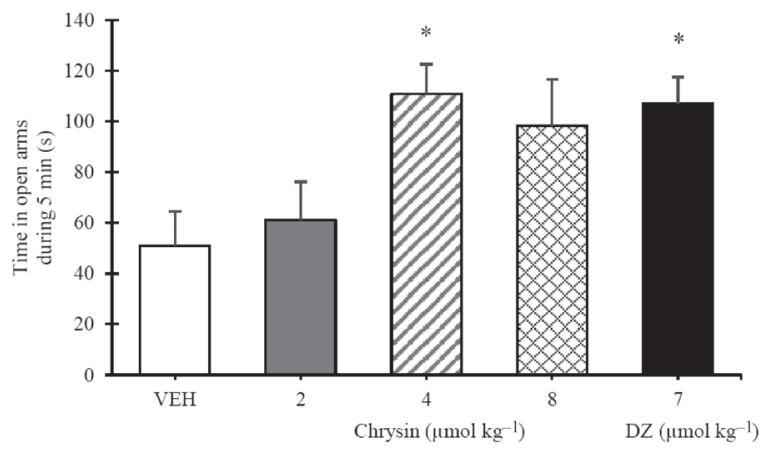

b)

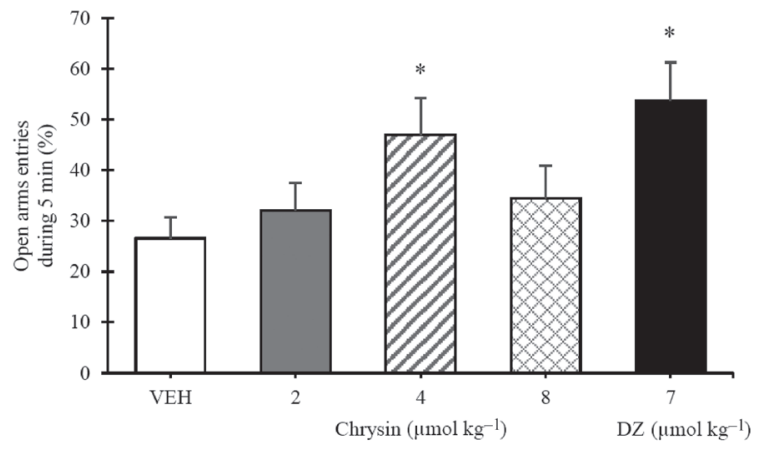

c)

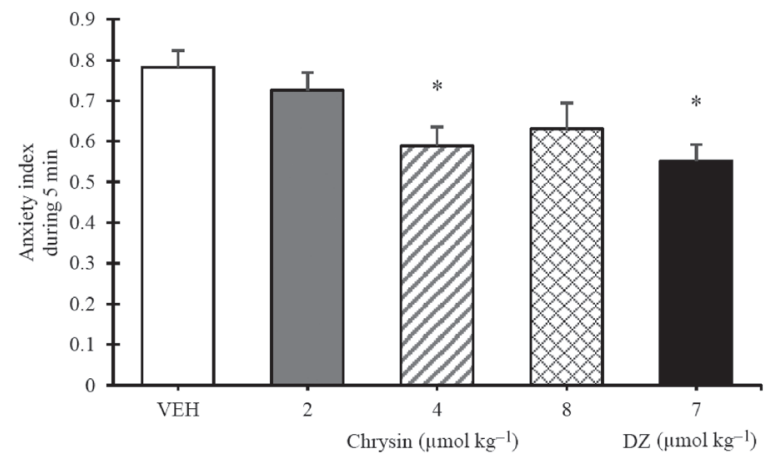

Fig. 2. Acute effect of chrysin in the elevated plus maze: a) time spent in the open arms, b) percentage of entries into the open arms, c) anxiety index. Significant difference $v$. vehicle group: ${ }^{*} p<0.05$. VEH - vehicle, DZ - diazepam.

ences were evidenced between treatments (vehicle and test groups) in regard to number of crossings during $5 \mathrm{~min}$, time spent rearing, and time spent grooming, thus confirming that the increase in the time and percentage of entries into the open arms in the EPM is associated with emotional, but not motor effects (16). 


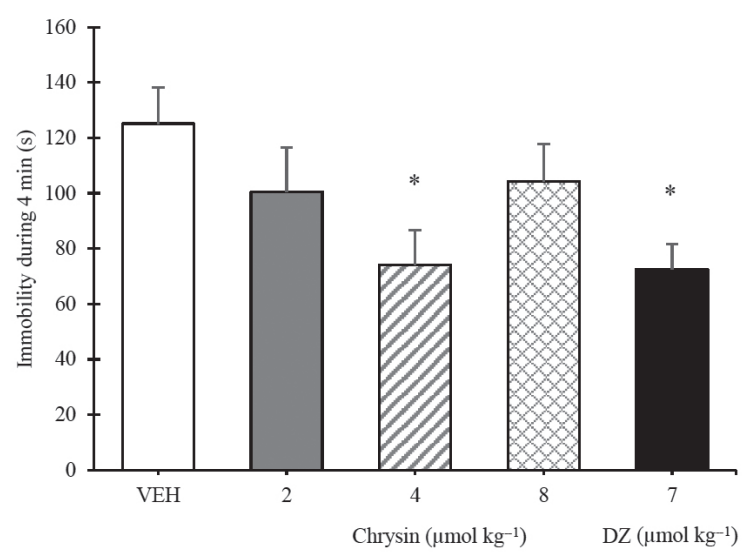

Fig. 3. Acute effect of chrysin and diazepam in the forced swim test. Significant difference $v$ s. vehicle group: ${ }^{*} p<0.05$. VEH - vehicle, DZ - diazepam.

Forced swim test. - In this test, substances with potential antidepressant-like effects (e.g., antidepressants and anxiolytics) significantly reduce immobility time (17). In the present study, the total immobility time was significantly different between the groups $\left(F_{4,40}=\right.$ 2.898, $p=0.034)$. Chrysin $\left(4 \mu \mathrm{mol} \mathrm{kg}{ }^{-1}\right)$ significantly $(p<0.05)$ decreased total immobility time compared to the vehicle group, an effect that was comparable to that of diazepam $\left(7 \mu \mathrm{mol} \mathrm{kg}{ }^{-1}\right)$ (Fig. 3), suggesting an antidepressant-like effect. However, this rapid effect does not necessarily represent an antidepressant-like effect because clinically effective antidepressants usually require at least several days of treatment to produce therapeutic effects. Therefore, a protective effect of chrysin and diazepam against stress-induced behavioral changes can be suggested, which could be related to anxiolytic-like effects detected in the EPM.

\section{Fos immunoreactivity in the LSN}

The analysis of Fos immunoreactivity in the LSN (dorsal, intermediate and ventral areas) revealed no significant differences among treatments. Therefore, we performed a global analysis of the total number of Fos-immunoreactive cells in the LSN in an area of $425,000 \mu \mathrm{m}^{2}$.

The evidence indicates that the LSN plays a critical role in the regulation of emotional states, including anxiety and depression (4). The analysis of Fos immunoreactivity in the whole LSN did not reveal a significant difference between groups. However, a marked tendency toward a decrease in this variable was observed in rats which were treated with 2 and $4 \mu \mathrm{mol} \mathrm{kg}{ }^{-1}$ chrysin and $7 \mu \mathrm{mol} \mathrm{kg}{ }^{-1}$ diazepam compared with the vehicle group ( $p=0.056$ ), an effect that was not observed with $8 \mu \mathrm{mol} \mathrm{kg}{ }^{-1}$ chrysin (Fig. 4). Considering the aforementioned, a previous study reported that higher dose of diazepam $\left(20 \mu \mathrm{mol} \mathrm{kg}{ }^{-1}\right)$ was required to significantly reduce Fos immunoreactivity in the LSN in anxious rats exposed to stressful situations $(6,18)$. This would explain why the acute and chronic doses of chrysin and diazepam (Fig. 5) used in the present study did not reach a 


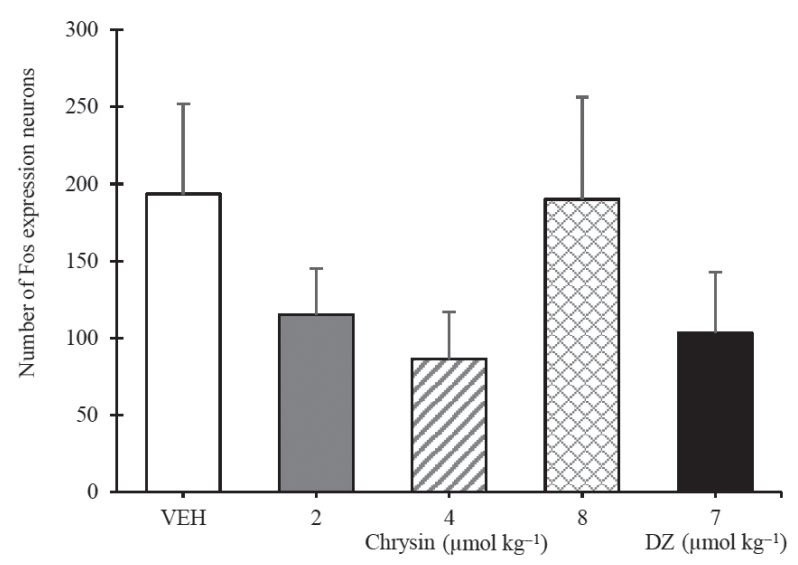

Fig. 4. The number of Fos immunoreactive cells in the LSN in acute chrysin and diazepam (area evaluated: $\left.425,000 \mu \mathrm{m}^{2}\right)$. VEH - vehicle, DZ - diazepam.

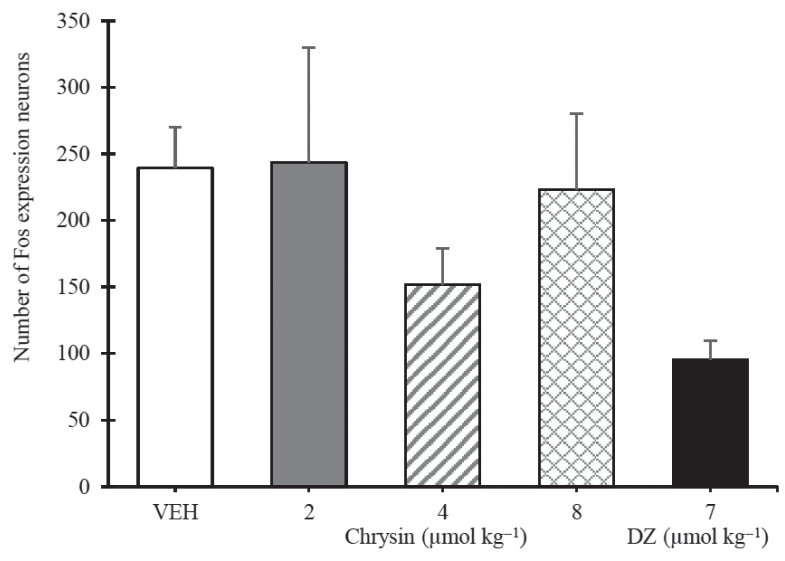

Fig. 5. The number of Fos immunoreactive cells in the LSN in chronic chrysin and diazepam administrations (area evaluated: $425,000 \mu \mathrm{m}^{2}$ ). VEH - vehicle, DZ - diazepam.

statistical significance. These data suggest a partial relationship between behavioral effects of chrysin and diazepam and a reduction of cellular activity in the LSN.

\section{Chronic effects of chrysin and diazepam}

Neither of the parameters in EPM (time spent on the open arms, number of entries into the open arms, total number of arm entries nor percentage of open arm entries), LAT (number of crossings, time spent rearing and time spent grooming), total immobility time in FST, nor the anxiety index was significantly different between treatments (vehicle and test groups) during chronic treatments. 


\section{Fos immunoreactivity in the LSN}

The analysis of the global number of Fos immunoreactive cells in the LSN showed no significant difference between treatments. However, this variable was significantly lower in rats which were treated with $4 \mu \mathrm{mol} \mathrm{kg}{ }^{-1}$ chrysin and $7 \mu \mathrm{mol} \mathrm{kg}^{-1}$ diazepam compared with the vehicle group. This effect was not observed in rats that were treated with 2 and 8 $\mu \mathrm{mol} \mathrm{kg}{ }^{-1}$ chrysin (Fig. 5).

In the present study, none of the chronic doses of chrysin or diazepam significantly affected the behavioral response in the EPM, LAT, FST, nor Fos immunoreactivity in the LSN. The lack of effects of chronic treatment may be associated with the development of pharmacological tolerance. Chrysin acts on $\mathrm{GABA}_{\mathrm{A}}$ receptor (1), and the repeated use of GABAergic substances (i.e., benzodiazepines) has been suggested to desensitize this receptor, thus causing the loss of their pharmacological efficacy in the long term (3). This may partially explain the loss of anxiolytic- and antidepressant-like effect of chronic treatment with chrysin and diazepam. Nonetheless, this possibility requires to be explored in specific studies.

Finally, no dose-response effects were detected with different doses of chrysin, but a biphasic effect was observed. Low and high doses of chrysin did not affect the evaluated variables; only the intermediate dose produced anxiolytic- and antidepressant-like effects, the same dose that produces anxiolytic-like effects in other studies (1). In the first case, it could be associated with insufficient availability of chrysin in the brain, whereas in the second case, high doses of the flavonoid could saturate the receptor and inactivate it. Similar findings were reported with several GABAergic compounds (i.e. neurosteroids, benzodiazepines, barbiturates, and plant extract containing flavonoids) whose action was established on the GABA receptor $(19,20)$, the same receptor in which chrysin exerts its pharmacological effects (1).

\section{CONCLUSIONS}

Acute, but not chronic treatment with the flavonoid chrysin produced anxiolytic-like and protective effects against behavioral changes that were produced by a stressful situation, and these effects were similar to diazepam. Moreover, the effects of chrysin were partially related to cellular changes in the LSN. Similar to anxiolytic benzodiazepine drugs, chrysin treatment appears to produce pharmacological tolerance after repeated use, which should be considered in future experimental protocols to confirm or discard this possibility.

Acknowledgements. - This study was partially supported by SEP-CONACyT through the Programa de Fortalecimiento Académico del Posgrado Académico de Alta Calidad (I010/458/2013, C703/2013, and I010/152/2014, C-133/2014) assigned to Juan Francisco Rodríguez-Landa. Leon Jesús Germán-Ponciano and Abraham Puga-Olguín received a fellowship from Consejo Nacional de Ciencia y Tecnología (CONACyT) for postgraduate studies in neuroethology (Reg. 297560 and 297410, resp.).

\section{REFERENCES}

1. C. Wolfman, H. Viola, H. Paladini, F. Dajas and J. H. Medina, Possible anxiolytic effects of chrysin, a central benzodiazepine receptor ligand isolated from Passiflora coerulea, Pharmacol. Biochem. Behav. 47 (1994) 1-4; https://doi.org/10.1016/0091-3057(94)90103-1 
L. J. Germán-Ponciano et al.: Differential effects of acute and chronic treatment with the flavonoid chrysin on anxiety-like behavior and Fos immunoreactivity in the lateral septal nucleus in rats, Acta Pharm. 70 (2020) 387-397.

2. C. B. Filho, C. R. Jesse, F. Donato, R. Giacomeli, L. Del Fabbro, M. da Silva Antunes, M. G. de Gomes, A. T. Goes, S. P. Boeira, M. Prigol and L. C. Souza, Chronic unpredictable mild stress decreases BDNF and NGF levels and $\mathrm{Na}^{+}, \mathrm{K}^{+}$-ATPase activity in the hippocampus and prefrontal cortex of mice: antidepressant effect of chrysin, Neuroscience 289 (2015) 367-380; https://doi. org/10.1016/j.neuroscience.2014.12.048

3. C. H. Vinkers and B. Olivier, Mechanisms underlying tolerance after long-term benzodiazepine

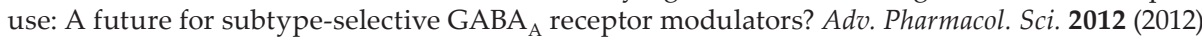
Article ID 416864 (19 pages); https://doi.org/10.1155/2012/416864

4. T. P. Sheehan, R. A. Chambers and D. S. Russell, Regulation of affect by the lateral septum: implications for neuropsychiatry, Brain. Res. Rev. 46 (2004) 71-117; https://doi.org/10.1016/j.brainresrev.2004.04.009

5. B. Gaszner, V. Kormos, T. Kozicz, H. Hashimoto, D. Reglodi and Z. Helyes, The behavioral phenotype of pituitary adenylate-cyclase activating polypeptide-deficient mice in anxiety and depression tests is accompanied by blunted c-Fos expression in the bed nucleus of the stria terminalis, central projecting Edinger-Westphal nucleus, ventral lateral septum, and dorsal raphe nucleus, Neuroscience 202 (2012) 283-299; https://doi.org/10.1016/j.neuroscience.2011.11.046

6. B. Lkhagvasuren, T. Oka, Y. Nakamura, H. Hayashi, N. Sudo and K. Nakamura, Distribution of Fos-immunoreactive cells in rat forebrain and midbrain following social defeat stress and diazepam treatment, Neuroscience 272 (2014) 34-57; https://doi.org/10.1016/j.neuroscience.2014.04.047

7. National Research Council, Guide for the Care and Use of Laboratory Animals, 7th ed., National Academy Press, Washington (DC) 1996.

8. Estados Unidos Mexicanos, Secretaría de Agricultura, Ganadería, Desarrollo Rural, Pesca y Alimentación, Norma Oficial Mexicana Nom-062-Zoo-1999, Especificaciones Tecnicas Para La Produccion, Cuidado y Uso de los Animales de Laboratorio, Diario Oficial (Primera Sección), pp. 107, Aug 22, 2001; https://www.gob.mx/cms/uploads/attachment/file/203498/NOM-062-ZOO-1999_220801.pdf; last access date July 30, 2019

9. C. M. Contreras, J. F. Rodríguez-Landa, R. I. García-Ríos, J. Cueto-Escobedo, G. Guillen-Ruiz and B. Bernal-Morales, Myristic acid produces anxiolytic-like effects in Wistar rats in the elevated plus maze, BioMed. Res. Int. 2014 (2014) Article ID 492141 (8 pages); https://doi.org/10.1155/2014/492141

10. W. M. S. Russell, R. L. Burch and C. W. Hume, The Principles of Humane Experimental Technique, Johns Hopkins Bloomberg School of Public Health, Baltimore 2005; http://altweb.jhsph.edu/pubs/ books/humane_exp/het-toc; last access date July 30, 2019

11. F. Borsini, Role of the serotonergic system in the forced swimming test, Neurosci. Biobehav. Rev. 19 (1995) 377-395; https://doi.org/10.1016/0149-7634(94)00050-B

12. M. Caba, M. Pabello, M. L. Moreno and E. Meza, Main and accessory olfactory bulbs and their projections in the brain anticipate feeding in food-entrained rats, Chronobiol. Int. 31 (2014) 869-877; https://doi.org/10.3109/07420528.2014.918625

13. G. Paxinos and C. Watson, The Rat Brain in Stereotaxic Coordinates, 4 th ed., Academic Press, New York 1998.

14. R. J. Rodgers, B. J. Cao, A. Dalvi and A. Holmes, Animal models of anxiety: an ethological perspective, Braz. J. Med. Biol. Res. 30 (1997) 289-304; https://doi.org/10.1590/S0100-879X1997000300002

15. J. F. Rodríguez-Landa, F. Hernández-López, J. Cueto-Escobedo, E. V. Herrera-Huerta, E. Rivadeneyra-Domínguez, B. Bernal-Morales and E. Romero-Avendaño, Chrysin (5,7-dihydroxyflavone) exerts anxiolytic-like effects through $\mathrm{GABA}_{\mathrm{A}}$ receptors in a surgical menopause model in rats, Biomed. Pharmacother. 109 (2019) 2387-2395; https://doi.org/10.1016/j.biopha.2018.11.111

16. S. Saiyudthong and C. A. Marsden, Acute effects of bergamot oil on anxiety-related behaviour and corticosterone level in rats, Phytother. Res. 25 (2011) 858-862; https://doi.org/10.1002/ptr.3325

17. J. Liu, J. C. Garza, J. Bronner, C. S. Kim, W. Zhang and X. Y. Lu, Acute administration of leptin produces anxiolytic-like effects: a comparison with fluoxetine, Psychopharmacology (Berlin) 207 (2010) 535-545; https://doi.org/10.1007/s00213-009-1684-3 
L. J. Germán-Ponciano et al.: Differential effects of acute and chronic treatment with the flavonoid chrysin on anxiety-like behavior and Fos immunoreactivity in the lateral septal nucleus in rats, Acta Pharm. 70 (2020) 387-397.

18. M. A. De Medeiros, L. C. Reis and L. E. Mello, Stress-induced c-Fos expression is differentially modulated by dexamethasone, diazepam and imipramine, Neuropsychopharmacology 30 (2005) 1246-1256; https://doi.org/10.1038/sj.npp.1300694

19. T. Backstrom, D. Haage, M. Lofgren, I. M. Johansson, J. Stromberg, S. Nyberg, L. Andreen, L. Ossewaarde, G. A. van Wingen, S. Turkmen and S. K. Bengtsson, Paradoxical effects of GABA-A modulators may explain sex steroid induced negative mood symptoms in some persons, Neurosciences 191 (2011) 46-54; https://doi.org/10.1016/j.neuroscience.2011.03.061

20. E. Estrada-Camarena, I. Sollozo-Dupont, D. Islas-Preciado, M. E. González-Trujano, M. CarroJuárez and C. López-Rubalcava, Anxiolytic- and anxiogenic-like effects of Montanoa tomentosa (Asteraceae): Dependence on the endocrine condition, J. Ethnopharmacol. 241 (2019) 112006; https:// doi.org/10.1016/j.jep.2019.112006 